\title{
Microbial Electrochemical Nutrient Recovery in Anaerobic Osmotic Membrane Bioreactors
}

\author{
by \\ Dianxun Hou ${ }^{1}$, Lu Lu ${ }^{1}$, Dongya Sun², Zheng Ge ${ }^{1}$, Xia Huang ${ }^{2}$, Tzahi Cath ${ }^{3}$, Zhiyong \\ Jason Ren ${ }^{1,}$
}

1. Department of Civil, Environmental, and Architectural Engineering, University of Colorado Boulder, Boulder, CO, USA

2. State Key Joint Laboratory of Environment Simulation and Pollution Control, School of Environment, Tsinghua University, Beijing, China

3. Department of Civil and Environmental Engineering, Colorado School of Mines, Golden, CO, USA

* Corresponding author address: Department of Civil, Environmental, and Architectural Engineering, University of Colorado Boulder, Boulder, CO, USA; Tel: +1 (303) 492 4137;

Fax: +1 (303) 492 7317; E-mail: zhiyong.ren@colorado.edu 


\section{Abstract}

40 This study demonstrates that by incorporating a microbial electrochemical unit into an

41 anaerobic osmotic membrane bioreactor (OMBR), the system addressed several

42 challenges faced by traditional anaerobic membrane bioreactors and recovered biogas,

43 nitrogen, and phosphorus while maintaining high effluent quality with low dissolved

44 methane. The microbial recovery cell (MRC)-OMBR system showed excellent organic 45 (>93\%) and phosphorus removal (>99\%) and maintained effluent COD below $20 \mathrm{mg} / \mathrm{L}$.

46 Furthermore, the reactor effectively recovered up to $65 \% \mathrm{PO}_{4}{ }^{3-}$ and $45 \% \mathrm{NH}_{4}{ }^{+}$from the 47 influent, which can be further improved if membranes with higher selectivity are used.

48 Nutrients removal from bulk solution mitigated $\mathrm{NH}_{4}{ }^{+}$penetration to the draw solution and 49 reduced scaling potential caused by $\mathrm{PO}_{4}{ }^{3-}$. The maximum methane yield was $0.19 \mathrm{~L}$ $50 \mathrm{CH}_{4} / \mathrm{g} \mathrm{COD}$, and low methane $(<2.5 \mathrm{~mL} \mathrm{CH} / \mathrm{L})$ was detected in the effluent. Further 51 improvement can be made by increasing charge efficiency for better nutrient and energy 52 recovery.

54 Keywords: forward osmosis, anaerobic osmotic membrane bioreactor, nutrient recovery, 55 microbial electrochemical technology, dissolved methane 


\section{Introduction}

58 Osmotic membrane bioreactors (OMBRs) have been gaining great interests for wastewater treatment and reuse. An OMBR integrates biological degradation of

60 wastewater substrates and a semi-permeable forward osmosis (FO) membrane for 61 physiochemical separation (Achilli et al. 2009, Cath et al. 2006, Chen et al. 2014, Gu et 62 al. 2015, Holloway et al. 2014, Holloway et al. 2015b, Lay et al. 2010). Water flows from 63 a low-salinity feed solution (FS) to a high-salinity draw solution (DS) through the non64 porous FO membrane, which acts as a barrier to the contaminants so the effluent 65 quality can be satisfactory. Most OMBR studies have focused on wastewater treatment 66 under aerobic conditions while only a few studies so far paid attention on anaerobic 67 OMBR process, which carries good potential for energy and resource recovery in addition of high quality treatment (Chen et al. 2014, Gu et al. 2015, Liu et al. 2017).

Anaerobic osmotic membrane bioreactor (AnOMBR) reduces energy demand and

71 recovers biogas or other renewable energy, and it can achieve high treatment efficiency

72 in low-strength wastewater while promoting anaerobic degradation in the reactor by 73 concentrating organic substrates (Chen et al. 2014). AnOMBR has several advantages 74 over conventional pressure-driven anaerobic membrane bioreactors (AnMBRs) that use 75 MF or UF membranes. Firstly, AnOMBR has shown lower fouling propensity due to the 76 absence of hydraulic pressures, which could compact the foulant layers and reduce 77 water permeation (Chen et al. 2014, Gu et al. 2015, Holloway et al. 2015a, Holloway et al. 2014, Holloway et al. 2015b, Lay et al. 2010). In addition, AnOMBR utilizes non79 porous semi-permeable FO membranes, which have the potential to alleviate several 
80 major problems faced by traditional AnMBRs, such as dissolved methane in the effluent

81 and low removal of soluble carbon, nitrogen, and phosphorus (Martinez-Sosa et al.

82 2011, Smith et al. 2013, Smith et al. 2012).

84 However, AnOMBRs still face challenges such as membrane fouling, bidirectional 85 solute diffusion, and effective approaches of nutrient recovery. Because anaerobic

86

87 reactors contain high concentrations of foluants, membrane fouling can be more severe compared to aerobic processes. Previous studies demonstrate that membrane fouling can be alleviated by coupling OMBRs with microbial fuel cells (MFCs) pretreatment. MFCs are anaerobic bioelectrochemical reactors that generate very small amount of biomass while producing electricity during biodegradation, so they can be complementary to OMBRs as they help decrease foulants concentration and condition sludge property thus reduce fouling (Hou et al. 2016, Tian et al. 2014). On the other hand, OMBR helps increase electrolyte conductivity which facilitates MFC electrochemical reaction kinetics and increases power generation (Hou et al. 2016).

In this study, we developed an integrated AnOMBR system that attempted to resolve several major challenges aforementioned such as effective nutrient $(N, P)$ recovery, biogas recovery, and reduce dissolved methane concentration in the effluent. We introduced a microbial electrochemical nutrient recovery unit into the OMBR, which we call a microbial recovery cell (MRC). The central hypothesis is that by taking advantage of the electrical potential generated across the anode and cathode in the MRC, charged ions such as $\mathrm{NH}_{4}{ }^{+}-\mathrm{N}, \mathrm{PO}_{4}{ }^{3-}-\mathrm{P}$ and salts can be extracted from the OMBR bulk solution 
103 and recovered in a separated recovery solution (Chen et al. 2015). Final product such 104 as struvite can be obtained (Qiu et al. 2016). This integration will minimize the 105 penetration of $\mathrm{NH}_{4}{ }^{+}$through the $\mathrm{FO}$ membrane thus improve effluent quality. In addition,

$106 \mathrm{PO}_{4}{ }^{3-}$ in the OMBR bulk is recovered, which reduces the scaling potential lead by $\mathrm{PO}_{4}{ }^{3-}$.

107 Presumably, incorporating MRC into OMBR may also recover $\mathrm{SO}_{4}{ }^{2-}$ from $\mathrm{OMBR}$ bulk 108 solution thus reduce methane loss due to sulfate reduction and improve methane yield. 109 Moreover, MRC not only recovers nutrients from OMBR but also desalinates OMBR 110 bulk solution, which reduces osmotic pressure loss and maintains FO membrane flux. In 111 the MRC-OMBR system, OMBR concentrates organics and solutes in the bulk and 112 increases buffer capacity. Such changes improve MRC current density, which in turn 113 increases the driving force of nutrient recovery and biogas production when a balance is 114 maintained between solute accumulation and removal. In addition, the produced biogas 115 could balance energy consumption needed for draw solution recovery. We also 116 investigated the dissolved methane in the bulk solution and draw solution (DS) and 117 characterized membrane fouling behavior.

\section{2. Material and methods}

\section{$120 \quad 2.1$ Membranes and Chemicals}

121 A commercial CTA FO membrane (Hydration Technology Innovations, Albany, OR) was 122 used in this study. The membrane has a water permeability of $2.08 \times 10^{-12} \mathrm{~m} / \mathrm{s} . P a$, a $123 \mathrm{NaCl}$ permeability of $1.76 \times 10^{-7} \mathrm{~m} / \mathrm{s}$, and a structure parameter of $0.48 \mathrm{~mm}$ (She et al. 124 2013, Zhang et al. 2014). Membrane coupons were soaked in MilliQ water (18.2 M $2 . \mathrm{cm}$ ) 125 at room temperature for over $24 \mathrm{~h}$ before use (She et al. 2013, Zhang et al. 2014). 
126 Glucose-based defined medium was used as the synthetic feed wastewater, so

127 degradation and current production mechanisms can be quantified (Gu et al. 2015, Hou

128 et al. 2016, Lu et al. 2014). The medium contained (mg/L): glucose, 200; yeast extract,

$12950 ; \mathrm{NaHCO}_{3}, 150 ; \mathrm{NH}_{4} \mathrm{Cl}, 80 ; \mathrm{KH}_{2} \mathrm{PO}_{4}, 50 ; \mathrm{Na}_{2} \mathrm{SO}_{4}, 40 ; \mathrm{MgCl}_{2} \cdot 6 \mathrm{H}_{2} \mathrm{O}, 5$; and $\mathrm{CaCl}_{2}, 10$.

130 The total soluble chemical oxygen demand (COD), $\mathrm{NH}_{3}-\mathrm{N}, \mathrm{PO}_{4}-\mathrm{P}$, electric conductivity

131 and $\mathrm{pH}$ of the feed solution were $275 \pm 10 \mathrm{mg} / \mathrm{L}, 21.6 \pm 0.5 \mathrm{mg} / \mathrm{L}, 13.0 \pm 0.2 \mathrm{mg} / \mathrm{L}, 0.57$

$132 \pm 0.05 \mathrm{mS} / \mathrm{cm}$ and $7.20 \pm 0.05$, respectively (Hou et al. 2016, Lu et al. 2014).

\subsection{Reactor Configuration and Operation}

135 The schematic diagram of the reactor system is shown in Figure 1. A microbial

136 electrochemical module and a FO membrane module (effective membrane area, $A_{m}$ :

$137272 \mathrm{~cm}^{2}$ ) with active layer facing feed orientation were fully submerged into a bioreactor

138 (effective volume, $V_{R}: 4.5 \mathrm{~L}$ ). The microbial electrochemical module was firstly 139 constructed in microbial electrolysis cell (MEC) configuration that consisted of two 140 carbon felt anodes (136 $\mathrm{cm}^{2}$ each) and a NiFe layered double hydroxide $\mathrm{Ni}$ foam 141 cathode $\left(136 \mathrm{~cm}^{2}\right.$ ), which was placed between the anodes (Lu et al. 2016a, Lu et al. 142 2016b). The MEC module was operated for biogas production for more than 30 days 143 after stabilization and then was switched to microbial recovery cell (MRC) mode for 144 nutrient recovery by adding two recovery chambers (total volume: $200 \mathrm{~mL}$ ) between the 145 anodes and cathodes with hydraulic connection. The recovery chamber was formed by 146 a cation exchange membrane (CEM, Excellion Ml-100, SnowPure, $136 \mathrm{~cm}^{2}$ ) and an 147 anion exchange membrane (AEM, Excellion MI-200, SnowPure, $136 \mathrm{~cm}^{2}$ ), facing the 148 anode and cathode, respectively (Forrestal et al. 2012). The glucose-based medium 
149 was directly fed into the bulk solution of the bioreactor. Nutrients were recovered via 150 MRC recovery chambers and clean water was recovered via FO draw solution. Biogas

151 was collected from bulk solution headspace. The anodes were inoculated with the 152 anaerobic digested sludge collected from Boulder Wastewater Treatment Plant and fed 153 with the synthetic wastewater. A voltage of $0.8 \mathrm{~V}$ was applied between the anode and 154 cathode with an external resistor $(R, 1 \Omega)$ inserted into the circuit for current monitoring 155 every 10 minutes using a data acquisition system (Keithley Instruments, Inc., $\mathrm{OH}$ ) 156 (Chookaew et al. 2014). A higher voltage of $1.0 \mathrm{~V}$ was applied at the end batch of MRC operation to investigate the effects of voltage. An air pump was used to recirculate the whole reactor was maintained at anaerobic condition and $25.0 \pm 0.5^{\circ} \mathrm{C}$. produced biogas through a gas diffuser in order to mix the solution and scour the FO membrane for fouling control, and the recirculation rate was controlled at $2 \mathrm{~L} / \mathrm{min}$. The During operation, the solution volume of the system was monitored by a digital balance. When the weight of the reactor dropped below the designated value, fresh feed 164 wastewater was transferred into the reactor using a peristaltic pump. Conductivity, 165 temperature, $\mathrm{pH}$, oxidation-reduction potential (ORP) values in the reactor were 166 monitored and logged using LabVIEW. In the meanwhile, draw solution (DS, $0.5 \mathrm{M} \mathrm{NaCl}$ ) 167 and/or nutrients recovery solution (NS, initial: $10 \mathrm{mM} \mathrm{NaCl}, 3.0 \mathrm{~L}$ ) were recirculated at a 168 flow rate of $560 \mathrm{~mL} / \mathrm{min}$ (equivalent to a cross flow velocity of $7.0 \mathrm{~cm} / \mathrm{s}$ ) and $50 \mathrm{~mL} / \mathrm{min}$, 169 respectively. The concentration of DS was monitored by conductivity measurements 170 and maintained constant through dosing a $5 \mathrm{M} \mathrm{NaCl}$ stock solution. The water flux was 171 determined gravimetrically by weighing the mass of permeate water collected at 172 predetermined time intervals with a digital balance (Ohaus, Parsippany, NJ). The 
173 membrane module was cleaned after each run by tap water flush and reused for next

174 operation; and after the final run, the membrane was taken out and characterized.

\subsection{Water and Solute Flux Modeling}

177 In order to simulate water flux and solute accumulation in OMBR, a water flux model 178 accounting concentration polarization was developed in our previous research.(Hou et al. 2016) Based on the model, the theoretical ratio of the accumulated solute flux from wastewater to the total solute accumulation $\left(\eta_{s}=22.6 \%\right.$ in this study) can be

181 determined using:

$$
\eta_{S}=\frac{J_{S_{-} F S}}{J_{S_{-} F S}+J_{S_{-} D S}}
$$

183 where $J_{S_{-} D S}$ is the reverse solute flux from draw solution, $J_{S_{-} F S}$ the accumulated solute 184 flux from wastewater. Experimentally, the contributions of solutes from wastewater to 185 the total solute accumulation $\left(\eta_{s}^{\prime}\right)$ in OMBR can be estimated using:

$$
\eta_{s}^{\prime}=\frac{E C_{0}\left(\frac{\int J_{w} A_{m} d t}{V_{R}}+1\right)}{E C_{t}+\sum_{1}^{t} \frac{V_{S}}{V_{R}}\left(E C_{t}-E C_{0}\right)}
$$
where $E C_{0}$ is the solution conductivity of fresh wastewater, $\int J_{w} A_{m} d t$ the cumulative 188 volume of water transport to the draw solution from the OMBR bulk solution at time $\mathrm{t}, V_{R}$ 189 the OMBR reactor volume, $E C_{t}$ the solution conductivity in OMBR at time t, and $V_{S}$ the 190 sampling volume at time t. The biological COD removal efficiency $\left(R_{C O D}\right)$, and the 191 overall removal efficiency $(R)$ and recovery efficiency $\left(\eta_{R}\right)$ of nutrients in the whole 192 MEC/MRC-OMBR system were calculated using Eq. (3), Eq. (4) and Eq. (5), 193 respectively. 


$$
R_{C O D}=1-\frac{\Delta C_{C O D, R} V_{R}+C_{C O D, D S} V_{D S}}{C_{C O D, F S} V_{F S}}
$$

$$
R=1-\frac{C_{D S}}{C_{F S}}
$$

$$
\eta_{R}=\frac{\Delta C_{N S} V_{N S}}{C_{F S} V_{F S}}
$$

198 where $C_{R}, C_{D S}, C_{F S}$ and $C_{N S}$ are the solutes and/or contaminants concentrations in the

199 reactor bulk, draw solution, feed solution and nutrient recovery solution, respectively;

200 and $V_{R}, V_{D S}, V_{F S}$, and $V_{N S}$ are the volume of OMBR reactor, draw solution, feed solution

201 and nutrient solution; $\Delta C_{R}$ and $\Delta C_{N S}$ are the concentration changes of solutes and/or

202 contaminants in the bulk reactor and nutrient recovery solution. Detailed descriptions of

$203 R$ and $\eta_{R}$ can be found elsewhere (Gu et al. 2015, Hou et al. 2016).

\subsection{Analyses}

206 All samples for COD, N and P measurements were centrifuged (5000 RPM for 5 min)

207 and then filtered through $0.45 \mu \mathrm{m}$ cellulose membranes (Millipore). COD was measured 208 according to standard methods described in detail by American Public Health 209 Association (APHA 1998). $\mathrm{NH}_{3}-\mathrm{N}$ (TNT 832/831/830) and $\mathrm{PO}_{4}-\mathrm{P}$ (TNT 846) were 210 measured with $\mathrm{HACH}$ test tubes $(\mathrm{HACH}$, Loveland, $\mathrm{CO})$. All samples were collected and 211 analyzed in triplicate.(Wang et al. 2011) The current and Coulombic efficiency (\%) of the

212 MEC/MRC were calculated according to previous studies (Luo et al. 2012b). In order to 213 determine the current utilization efficiency of certain nutrient ions, charge efficiency was 214 defined as ratio of the electric charge of the recovered ion to the total charge introduced 215 by the current (Chen et al. 2015). 
217 Biogas (250 $\mu \mathrm{L}$ samples) in the reactor headspace was sampled using a gastight

218 syringe $(500 \mu \mathrm{L}$; Hamilton Samplelock Syringe) and analyzed using a gas 219 chromatograph (8610C, SRI Instruments) for $\mathrm{H}_{2}, \mathrm{CH}_{4}$ and $\mathrm{CO}_{2}$. Dissolved methane was 220 also measured by transferring a liquid sample $(10 \mathrm{~mL})$ from OMBR or DS tank into a 221 serum bottle (12.5 mL, HACH, Loveland, CO), leaving a headspace of $2.5 \mathrm{~mL}$; the 222 headspace air was replaced by $\mathrm{N}_{2}$ gas and the bottle was sealed with a thick butyl 223 rubber stopper (20 mm diameter, Chemglass Inc.). After establishing gas-liquid 224 equilibrium by shaking the serum bottle for 24 hours at room temperature, the amount of 225 dissolved methane was back-calculated from the measured methane amount in the 226 headspace according to Henry's Law (Ren et al. 2014). All serum bottles were 227 autoclaved, and all liquid samples were collected in triplicate and filtered using $0.2 \mu \mathrm{m}$ 228 cellulose membranes (Millipore) to prevent biological activities. Paired two-sample $t$-test 229 was performed to study the significance of methane yield improvement.

\section{3. Results and discussion}

\section{3.1. Reactor Water Flux Change, Salinity Accumulation, and Membrane Fouling}

233 Figure 2 shows the time-course change of water flux and solution conductivity in the 234 OMBR. Varied in different operations, within one stage ( 11 days) the solution 235 conductivity could increase dramatically from $0.7 \pm 0.05$ to $17.0 \pm 0.2 \mathrm{mS} / \mathrm{cm}$ during MEC-

236 OMBR operation or to $12.7 \pm 0.2 \mathrm{mS} / \mathrm{cm}$ during MRC-OMBR operation. The increase of 237 solution conductivity was partially due to solutes accumulation from wastewater (i.e., $238 \mathrm{NaCl}, \mathrm{NaHCO}_{3}, \mathrm{KH}_{2} \mathrm{PO}_{4}, \mathrm{Na}_{2} \mathrm{SO}_{4}$ ) during $\mathrm{FO}$ water extraction. Our previous study 239 quantified that salt accumulation in the wastewater FS contributed $82.1 \pm 4.0 \%\left(\eta_{s}\right)$ of 
240 the salinity build-up in an OMBR with TFC membranes (Hou et al. 2016). However, we

241 found in this study that when CTA membrane was used, such contribution of salt

242 accumulation only accounted for $\eta_{s} "=25.1 \pm 3.0 \%$ (Figure S2), which is much smaller

243 than the contribution from reversely diffused solutes (i.e., $\mathrm{NaCl}$ ). Such difference is due

244 to the intrinsic low-rejection property of CTA membranes (Chen et al. 2014, Gu et al.

245 2015, Xiao et al. 2011). The lower salinity buildup in MRC-OMBR than the MEC-OMBR 246 operation was due to ion migration across the ion exchange membranes into the 247 recovery solution (Chen et al. 2015, Luo et al. 2011). This is confirmed by the 248 conductivity change of the recovered nutrient solution, which increased from $1.10 \pm 0.05$

$249 \mathrm{mS} / \mathrm{cm}$ to $11.25 \pm 0.25 \mathrm{mS} / \mathrm{cm}$ under $0.8 \mathrm{~V}$ or $12.86 \mathrm{mS} / \mathrm{cm}$ under $1.0 \mathrm{~V}$, respectively.

250 Previous studies demonstrated that the alleviation of salinity reduces its potential 251 toxicity on microbial activities, and it also alleviates membrane fouling by decreasing 252 protein concentration in the soluble microbial products (SMPs), as well as affecting the 253 charge interactions between foulant-foulant and/or foulant-membrane (Chen et al. 2014, 254 Hong and Elimelech 1997).

255

256 Corresponding to salinity build up in the OMBR bulk, water flux decreased from $8.7 \pm 0.3$ 257 to $4.0 \pm 0.2 \mathrm{LMH}$ in 13 days. The experimental flux profile matches the modeled flux, 258 which simulates the flux under solute conductivity build-up without considering 259 membrane fouling. This is attributed to the low fouling property of CTA membrane as 260 well as fouling mitigation carried by MEC/MRC. The flux decline was also slower than 261 that in an MFC-OMBR system equated with thin-film composite (TFC) membrane.(Hou 262 et al. 2016) All these reveal that CTA membrane is less prone to fouling than TFC 
263 membrane, which can be attributed to CTA membrane's smoother surface and less

264 binding properties with the fouling precursors (e.g., divalent ions) (Gu et al. 2013, Mi

265 and Elimelech 2008, Mi and Elimelech 2010). The less fouling property of CTA was also

266 supported by the fact that almost a full recovery of flux $(97.3 \pm 0.7 \%)$ was obtained after

267 each cleaning using tap water.

268

269 Visual inspection and electron microscopy were performed on FO membrane coupons.

270 Visual examinations of virgin and fouled membrane samples after one cycle are

271 illustrated in Figure S3. The observed foulant layer is thin and loose, which can be

272 easily removed from membrane surface by water rinsing. More importantly, the SEM

273 images (Figure S3) indicate that biofouling/organic fouling contributed higher to

274 membrane flux decline than inorganic scaling. This is different from results obtained in

275 other studies, in which crystal deposition was abundantly observed in the foulant layer

276 (Gu et al. 2015). Further research will be conducted in order to reveal the inorganic

277 scaling behavior in the MEC/MRC-OMBR systems.

278 3.2. Organic Removal and Nutrients Recovery

279 Figure 3 shows the changes of COD concentration in the bulk solution and draw 280 solution of OMBR. High COD removal (>93\%) was accomplished in both stages of 281 operation, and the COD in the OMBR draw solution maintained below $20 \mathrm{mg} / \mathrm{L}$ due to 282 the good rejection performance $(>90 \%)$ by the CTA membrane. One interesting finding 283 is that different from many studies where continued COD decrease was observed, COD

284 in the bulk solution increased first during each batch till it reached to a peak then it 285 started to drop till the end of the batch. This bell shaped profile is presumably related to 
286 the interaction between FO concentration and biological degradation of organics. 287 Initially, COD in the bulk solution increased because the concentration factor of FO 288 overweighed the biodegradation of COD in the bulk solution, which resulted in the 289 accumulation of COD. However, overtime the flux declined due to slower mass transfer 290 and membrane fouling (Figure 2), while biodegradation rate increased, therefore COD 291 removal became dominant after the peak (Brown et al. 2015, Hou et al. 2016). This can 292 also be observed in Figure 5B, in which the relationships among COD, conductivity and 293 current are illustrated. Smaller peaks were observed in MRC-OMBR operation, which is 294 likely due to the removal of charged organics such as volatile fatty acids during nutrient 295 recovery. Figure 4 shows the changes of nutrients $\left(\mathrm{NH}_{3}-\mathrm{N}\right.$ and $\left.\mathrm{PO}_{4}-\mathrm{P}\right)$ in the OMBR bulk solution, draw solution and nutrient recovery solution. During the MEC-OMBR stage, $\mathrm{NH}_{3}-\mathrm{N}$ concentration in OMBR bulk solution initially increased due to accumulation then dropped due to the migration of $\mathrm{NH}_{3}-\mathrm{N}$ to the $\mathrm{DS}$. The limited removal of $\mathrm{NH}_{3}-\mathrm{N}$ in 301 AnOMBR is widely observed in previous studies, which is partially due to the lack of 302 biological degradation in anaerobic condition but also the low rejection of $\mathrm{NH}_{3}-\mathrm{N}$ by CTA membrane (Chen et al. 2014, Gu et al. 2015). The pH increase in bulk solution $(6.7 \pm 0.2$ to $7.8 \pm 0.2$, Figure S4) also played a role as it affects $\mathrm{NH}_{4}{ }^{+} / \mathrm{NH}_{3}$ distribution and lead to higher flux of $\mathrm{NH}_{3}-\mathrm{N}$ in the form of $\mathrm{NH}_{3}$ toward the draw solution. Because MEC does 306 not have nutrient recovery function, the majority of nitrogen in bulk solution migrated to 307 FO draw solution, but the performance of CTA in $\mathrm{NH}_{3}-\mathrm{N}$ rejection was actually better 308 than that of TFC membrane reported in previous studies, because the deprotonation of 309 carboxylic groups on TFC membranes leads a negatively charged surface, which 
310 promotes diffusion of cations (e.g., $\mathrm{NH}_{4}^{+}$) from OMBR bulk solution to DS (Hou et al.

311 2016, Lu et al. 2014, Xue et al. 2015). In contrast, the MRC-OMBR stage showed much

312 better $\mathrm{NH}_{3}-\mathrm{N}$ removal with its concentration in bulk solution dropped from $\sim 75 \mathrm{mg} / \mathrm{L}$ to

$313 \sim 50 \mathrm{mg} / \mathrm{L}$ and the concentration in DS dropped from $\sim 21 \mathrm{mg} / \mathrm{L}$ to $\sim 16 \mathrm{mg} / \mathrm{L}$. The

314 removed nitrogen was recovered in the MRC recovery solution, in which $\mathrm{NH}_{3}-\mathrm{N}$

315 increased from 0 up to $80 \mathrm{mg} / \mathrm{L}$, representing a nitrogen recovery efficiency between $31628-45 \%$.

318 In contrast to the low rejection and removal of $\mathrm{NH}_{3}-\mathrm{N}$ due to membrane limitation, the 319 MEC/MRC-OMBR showed almost perfect rejection (> 99\%) and removal (> 99\%) of $320 \mathrm{PO}_{4}-\mathrm{P}$ (Figure 4B). $\mathrm{PO}_{4}-\mathrm{P}$ in DS cannot be detected, and the concentration of $\mathrm{PO}_{4}-\mathrm{P}$ 321 increased from 13.0 up to $280 \mathrm{mg} / \mathrm{L}$ for MEC-OMBR in one batch. The high $\mathrm{PO}_{4}{ }^{3-}$ may 322 react with other cations $\left(\mathrm{NH}_{4}{ }^{+}, \mathrm{Mg}^{2+}\right.$, and $\left.\mathrm{Ca}^{2+}\right)$ to form $\mathrm{Ca}_{3}\left(\mathrm{PO}_{4}\right)_{2}$ and/or struvite (i.e., $323 \mathrm{NH}_{4} \mathrm{MgPO}_{4} \cdot 6 \mathrm{H}_{2} \mathrm{O}$ ) (Gu et al. 2015). The MRC-OMBR recovered 41-65\% $\mathrm{PO}_{4}-\mathrm{P}$ from 324 the bulk solution to the recover solution by the end of each stage, which enables 325 nutrients recovery and alleviates scaling potential. Mass balance calculation details can 326 be found in Supporting Information.

328 It is interesting to note that $\mathrm{NH}_{3}-\mathrm{N}$ and $\mathrm{PO}_{4}-\mathrm{P}$ concentration in the OMBR bulk solution 329 tended to stabilize after 6 days. This might be due to electroosmosis as well as the 330 competitive effects between the potential gradient and the concentration gradient across

331 the ion exchange membranes, which drive the diffusion of $\mathrm{NH}_{3}-\mathrm{N}$ and $\mathrm{PO}_{4}-\mathrm{P}$ in reverse 332 directions (Pronk et al. 2006). Another reason can be revealed using charge efficiency 
333 (Figure S5), which is defined as the electric charges of those recovered ions to the total 334 electric charges induced by the current (Chen et al. 2015). The initial charge efficiencies

335 for $\mathrm{NH}_{4}{ }^{+}$and $\mathrm{PO}_{4}{ }^{3-}$ in MRC-OMBR were $\sim 10 \%$ and $6 \%$ (Figure S5A), respectively,

336 which were comparable to the results reported in previous studies $\left(\mathrm{NH}_{4}{ }^{+}: 15.5 \%\right.$ and $\left.337 \mathrm{PO}_{4}{ }^{3-}: 6.3 \%\right)$ (Chen et al. 2015). However, the charge efficiencies decreased to low 338 level along with operation. Previous research showed that ion migration across the 339 membrane can be affected by the mobility, concentration of ions, and the electrical field 340 intensity and membrane selectivity (Luo et al. 2012a). Accordingly, the loss of charge 341 efficiency for $\mathrm{NH}_{4}{ }^{+}$and $\mathrm{PO}_{4}{ }^{3-}$ might be majorly caused by the accumulation and 342 competition of other ions, especially $\mathrm{Na}^{+}$and $\mathrm{Cl}^{-}$, which are the predominant ions in the 343 OMBR bulk solution (Figure S2 and Figure S5B). It is interesting that owing to the 344 increased current, the recovery ratios of $\mathrm{NH}_{4}{ }^{+}$and $\mathrm{PO}_{4}{ }^{3-}$ remained stable $(\sim 40 \%$, 345 Figure 4B) in the first 6-8 days, and increased up to $60 \%$, respectively. While this 346 demonstrates that MRC and OMBR has mutual benefits for more efficient nutrients 347 recovery, further studies can be conducted to better understand the competitive 348 migration characteristics, and more efficient MRC (e.g., higher current and higher $\mathrm{NH}_{3}-\mathrm{N}$ selectivity) can be configured for enhanced $\mathrm{NH}_{3}-\mathrm{N}$ recovery.

\subsection{Current and Biogas Production}

352 Figure 5A shows the current and Coulombic efficiency of the system. For both stages, 353 the current increased in the first few days due to the increase in solution conductivity 354 (Figure 2), COD (Figure 3), and buffer capacity (Figure 4A and Figure S4) (Hou et al. 355 2016, Nam et al. 2010). Because MRC has higher internal resistance than MEC due to 356 the presence of membranes and increased distance between electrodes, MRC-OMBR 
357 showed smaller current. Increasing the applied voltage in MRC boosted the current

358 (Figure 5A). Similar to the bell curve shaped COD profiles in Figure 3, the current 359 profiles also showed initial increase then decline. This is mainly caused by the depletion 360 of substrates, below which the COD level was not enough to support high current 361 production (Hou et al. 2016, Zhang et al. 2015). Similar trends were observed in 362 Coulombic efficiency, which increased from $20 \pm 1 \%$ up to $60 \pm 2 \%$ and then decreased 363 and stabilized around $40 \pm 1 \%$. Such changes can also be related to the interactions of 364 solution conductivity, buffer capacity, substrate availability, and microbial competition 365 (Hou et al. 2016, Zhang et al. 2015). Nevertheless, the Coulombic efficiency in this 366 research is much higher than that in our previously reported MFC-OMBR system in 367 which air-cathode was used. Figure 5B shows the interactive effects of COD and 368 solution conductivity on the current production of MEC-OMBR. It can be seen that in the 369 concentration range used in this study (COD $<500 \mathrm{mg} / \mathrm{L}$, E.C. $<20 \mathrm{mS} / \mathrm{cm}$ ), increasing 370 COD and solution conductivity boosted current production.

372 In addition to organic removal and nutrient recovery, the anaerobic system also 373 generated biogas as a renewable energy source. It can be seen from Figure 6 that 374 methane yield (volume of methane produced per gram COD removed) increased during 375 MEC-OMBR operation as methanogens started to acclimate. The highest methane yield 376 was about $0.15 \mathrm{~L} \mathrm{CH}_{4} / \mathrm{g} \mathrm{COD}$, representing $50 \%$ of the maximal theoretical value. The 377 methane yield is comparable to the values reported in previous literature on anaerobic 378 OMBRs or MBRs, in which methane yields ranged from 0.15 to $0.25 \mathrm{~L} \mathrm{CH}_{4} / \mathrm{g}$ COD 379 when treating municipal wastewater at $20-35{ }^{\circ} \mathrm{C}$ (Chen et al. 2014 , Martinez-Sosa et al. 
2011). $\mathrm{H}_{2}$ production was negligible during the operation so its production was not accounted into biogas production. It was reported previously that methane losses (28\% to $39 \%$ ) in MBRs can be due to the activity sulfate reducing bacteria, dissolved 383 oversaturation, and the loss of dissolved methane in the effluent (Smith et al. 2013, 384 Smith et al. 2012). However, methane oversaturation was not observed in this study, 385 and dissolved methane in the reactor was consistently below $8 \mathrm{~mL} \mathrm{CH} / \mathrm{L}$ (Figure 6). 386 This can be attributed to the use of biogas sparging to reduce mass-transfer limitations 387 between the gas and liquid-phases (Gimenez et al. 2012). More importantly, the dissolved methane in the DS was always below $2.5 \mathrm{~mL} \mathrm{CH}_{4} / \mathrm{L}$, which is much lower than reported dissolved methane in conventional MBRs(Gimenez et al. 2012, Martinez-Sosa et al. 2011, Smith et al. 2013, Smith et al. 2012). The low methane permeation can be 391 attributed to the rejection by the CTA FO membrane (Donohue et al. 1989). Moreover, 392 low fouling propensity of FO membrane reduces biofilm attachment including 393 methanogens on the membrane, which reduced the in situ methane oversaturation on 394 the membrane surface thus methane permeation. Therefore, it is believed that FO 395 membrane processes advantages over conventional pressure driven porous 396 membranes, such as MF and UF, in mitigating methane loss. It is interesting that 397 compiling MRC into OMBR showed improved methane yield $(P<0.05)$. This is likely 398 due to sulfate recovery from OMBR bulk by MRC, which mitigated methane loss due to 399 sulfate reduction (Figure 6). Though the recovered sulfate was not characterized in this 400 research, previous research reported the recovery of sulfate by MRC (Chen et al. 2015). 401 In addition, desalination of OMBR bulk solution by MRC might also mitigate 402 methanogen inhibition from salinity build-up, which reduced the conversion of substrate 
403 to extracellular polysaccharides under high osmotic conditions (Chen et al. 2014).

404 Further optimization needs to be performed to improve gas production and collection.

405 Nevertheless, MEC/MRC-OMBR showed superiorities over the conventional MBR in 406 treating low-strength wastewater, in which no measurable biogas production was 407 observed at influent COD <225 mg/L (Smith et al. 2013, Smith et al. 2012).

\section{Conclusions}

410 The incorporation of electrochemical nutrient recovery process in anaerobic osmotic

411 membrane reactor improved effluent quality, energy production, and resource recovery

412 compared to traditional membrane processes. The removal of charged ions from OMBR

413 bulk solution also alleviated osmotic pressure drop and improved water flux, as well as

414 reduced scaling potential. In addition, different from conventional AnMBR reactors,

415 methane oversaturation was not observed in the MEC/MRC-OMBR, and the dissolved

416 methane in the draw solution was maintained at low level.

418 While the study demonstrates the feasibility and benefits of integrating nutrient recovery 419 with OMBR, more works are needed to optimize system configuration and performance.

420 Similar to most OMBR reactors, the limited rejection of ammonium by FO membranes 421 leads to the presence of ammonium in draw solution effluent. The integration of MRC in 422 FO reduced such migration by approximately $50 \%$, but new membrane and solute 423 development are needed in order to reduce $\mathrm{NH}_{3}-\mathrm{N}$ penetration through the membrane 424 (Lu et al. 2014, Devia et al. 2015). Also, draw solution can be further processed with 425 post treatment using reverse osmosis or membrane distillation to generate pure water. 426 The geometry of MRC-OMBR (e.g., submerged or in series) can be adjusted to improve 
427 charge efficiency of nutrient ions, and the recovered nutrients can be processed for 428 struvite precipitation (Qiu et al. 2016, Xie et al. 2014, Xie et al. 2016) or biochar 429 adsorption (Huggins et al. 2016). Different operational conditions need to be tested such 430 as low temperature, high organic loading, and different retention times (Heidrich et al.

431 2014, Lettinga et al. 1999). Optimizations can also be optimized by modeling membrane 432 flux, solute accumulation, and solute recovery/desalination of the system, all of which 433 are key factors affecting reactor treatment performance.

434

435 Acknowledgements

436 We appreciate the financial support from the Office of Naval Research 437 (N000141310901) and National Science Foundation (IIP-1445084). 
441

442

443

444

445

446

447

448

449

450

451

452

453

454

455

456

457

458

459

460

461

462

463

464

465

466

467

468

469

470

471

472

473

474

475

476

477

478

479

480

481

482

483

Achilli, A., Cath, T.Y., Marchand, E.A. and Childress, A.E. (2009) The forward osmosis membrane bioreactor: a low fouling alternative to MBR processes. Desalination 239(1-3), 10-21.

APHA (1998) Standard ethods for the examination of water and wastewater, 20th Edition, APHA American Public Health Association.

Brown, R.K., Harnisch, F., Dockhorn, T. and Schröder, U. (2015) Examining sludge production in bioelectrochemical systems treating domestic wastewater. Bioresource Technology 198, 913-917.

Cath, T.Y., Childress, A.E. and Elimelech, M. (2006) Forward osmosis: principles, applications, and recent developments. Journal of Membrane Science 281(1-2), 7087.

Chen, L., Gu, Y.S., Cao, C.Q., Zhang, J., Ng, J.W. and Tang, C.Y. (2014) Performance of a submerged anaerobic membrane bioreactor with forward osmosis membrane for low-strength wastewater treatment. Water Research 50, 114-123.

Chen, X., Sun, D., Zhang, X., Liang, P. and Huang, X. (2015) Novel self-driven microbial nutrient recovery cell with simultaneous wastewater purification. Scientific Reports 5, 15744.

Chookaew, T., Prasertsan, P. and Ren, Z.J. (2014) Two-stage conversion of crude glycerol to energy using dark fermentation linked with microbial fuel cell or microbial electrolysis cell. New Biotechnology 31(2), 179-184.

Devia, Y.P., Imai, T., Higuchi, T., Kanno, A., Yamamoto, K., Sekine, M. and Van Le, T. (2015) Potential of magnesium chloride for nutrient rejection in forward osmosis. Journal of Water Resource and Protection 7(09), 730.

Donohue, M.D., Minhas, B.S. and Lee, S.Y. (1989) Permeation behavior of carbon dioxide-methane mixtures in cellulose acetate membranes. Journal of Membrane Science 42(3), 197-214.

Forrestal, C., Xu, P., Jenkins, P.E. and Ren, Z.Y. (2012) Microbial desalination cell with capacitive adsorption for ion migration control. Bioresource Technology 120, 332336.

Gimenez, J.B., Marti, N., Ferrer, J. and Seco, A. (2012) Methane recovery efficiency in a submerged anaerobic membrane bioreactor (SAnMBR) treating sulphate-rich urban wastewater: Evaluation of methane losses with the effluent. Bioresource Technology 118, 67-72.

Gu, Y.S., Chen, L., Ng, J.W., Lee, C., Chang, V.W.C. and Tang, C.Y.Y. (2015) Development of anaerobic osmotic membrane bioreactor for low-strength wastewater treatment at mesophilic condition. Journal of Membrane Science 490, 197-208.

Gu, Y.S., Wang, Y.N., Wei, J. and Tang, C.Y.Y. (2013) Organic fouling of thin-film composite polyamide and cellulose triacetate forward osmosis membranes by oppositely charged macromolecules. Water Research 47(5), 1867-1874.

Heidrich, E.S., Edwards, S.R., Dolfing, J., Cotterill, S.E. and Curtis, T.P. (2014) Performance of a pilot scale microbial electrolysis cell fed on domestic wastewater at ambient temperatures for a 12 month period. Bioresource Technology 173, 87-95. 
Holloway, R.W., Achilli, A. and Cath, T.Y. (2015a) The osmotic membrane bioreactor: a critical review. Environmental Science: Water Research \& Technology 1(5), 581-605.

Holloway, R.W., Regnery, J., Nghiem, L.D. and Cath, T.Y. (2014) Removal of trace organic chemicals and performance of a novel hybrid ultrafiltration-osmotic membrane bioreactor. Environmental Science \& Technology 48(18), 10859-10868.

Holloway, R.W., Wait, A.S., da Silva, A.F., Herron, J., Schutter, M.D., Lampi, K. and Cath, T.Y. (2015b) Long-term pilot scale investigation of novel hybrid ultrafiltrationosmotic membrane bioreactors. Desalination 363, 64-74.

Hong, S.K. and Elimelech, M. (1997) Chemical and physical aspects of natural organic matter (NOM) fouling of nanofiltration membranes. Journal of Membrane Science 132(2), 159-181.

Hou, D.X., Lu, L. and Ren, Z.J. (2016) Microbial fuel cells and osmotic membrane bioreactors have mutual benefits for wastewater treatment and energy production. Water Research 98, 183-189.

Huggins, T.M., Haeger, A., Biffinger, J.C. and Ren, Z.J. (2016) Granular biochar compared with activated carbon for wastewater treatment and resource recovery. Water Research 94, 225-232.

Lay, W.C.L., Liu, Y. and Fane, A.G. (2010) Impacts of salinity on the performance of high retention membrane bioreactors for water reclamation: a review. Water Research 44(1), 21-40.

Lettinga, G., Rebac, S., Parshina, S., Nozhevnikova, A., van Lier, J.B. and Stams, A.J.M. (1999) High-rate anaerobic treatment of wastewater at low temperatures. Applied and Environmental Microbiology 65(4), 1696-1702.

Liu, J., Wang, X., Wang, Z., Lu, Y., Li, X. and Ren, Y. (2017) Integrating microbial fuel cells with anaerobic acidification and forward osmosis membrane for enhancing bioelectricity and water recovery from low-strength wastewater. Water Research 110, 74-82.

Lu, L., Hou, D., Wang, X., Jassby, D. and Ren, Z.J. (2016a) Active $\mathrm{H}_{2}$ harvesting prevents methanogenesis in microbial electrolysis cells. Environmental Science \& Technology Letters 3(8), 286-290.

Lu, L., Hou, D.X., Fang, Y.F., Huang, Y.P. and Ren, Z.J. (2016b) Nickel based catalysts for highly efficient $\mathrm{H}_{2}$ evolution from wastewater in microbial electrolysis cells. Electrochimica Acta 206, 381-387.

Lu, L., Huang, Z., Rau, G.H. and Ren, Z.J. (2015) Microbial electrolytic carbon capture for carbon negative and energy positive wastewater treatment. Environmental Science \& Technology 49(13), 8193-8201.

Lu, L., Yazdi, H., Jin, S., Zuo, Y., Fallgren, P., Ren, Z.J. (2014) Enhanced bioremediation of hydrocarbon-contaminated soil using pilot-scale bioelectrochemical systems. Journal of Hazardous Materials 274, 8-15.

Lu, X.L., Boo, C., Ma, J. and Elimelech, M. (2014) Bidirectional diffusion of ammonium and sodium cations in forward osmosis: role of membrane active layer surface chemistry and charge. Environmental Science \& Technology 48(24), 14369-14376.

Luo, H.P., Jenkins, P.E. and Ren, Z.Y. (2011) Concurrent desalination and hydrogen generation using microbial electrolysis and desalination cells. Environmental Science \& Technology 45(1), 340-344. 
Luo, H.P., Xu, P., Jenkins, P.E. and Ren, Z.Y. (2012a) lonic composition and transport mechanisms in microbial desalination cells. Journal of Membrane Science 409, 16 23.

Luo, H.P., Xu, P., Roane, T.M., Jenkins, P.E. and Ren, Z.Y. (2012b) Microbial desalination cells for improved performance in wastewater treatment, electricity production, and desalination. Bioresource Technology 105, 60-66.

Martinez-Sosa, D., Helmreich, B., Netter, T., Paris, S., Bischof, F. and Horn, H. (2011) Anaerobic submerged membrane bioreactor (AnSMBR) for municipal wastewater treatment under mesophilic and psychrophilic temperature conditions. Bioresource Technology 102(22), 10377-10385.

Mi, B. and Elimelech, M. (2008) Chemical and physical aspects of organic fouling of forward osmosis membranes. Journal of Membrane Science 320(1-2), 292-302.

Mi, B.X. and Elimelech, M. (2010) Gypsum scaling and cleaning in forward osmosis: measurements and mechanisms. Environmental Science \& Technology 44(6), 20222028.

Pronk, W., Biebow, M. and Boller, M. (2006) Electrodialysis for recovering salts from a urine solution containing micropollutants. Environmental Science \& Technology 40(7), 2414-2420.

Qiu, G.L., Zhang, S., Shankari, D., Raghavan, S., Das, S. and Ting, Y.P. (2016) The potential of hybrid forward osmosis membrane bioreactor (FOMBR) processes in achieving high throughput treatment of municipal wastewater with enhanced phosphorus recovery. Water Research 105, 370-382.

Ren, L.J., Ahn, Y. and Logan, B.E. (2014) A two-stage microbial fuel cell and anaerobic fluidized bed membrane bioreactor (MFC-AFMBR) system for effective domestic wastewater treatment. Environmental Science \& Technology 48(7), 4199-4206.

She, Q.H., Hou, D.X., Liu, J.X., Tan, K.H. and Tang, C.Y.Y. (2013) Effect of feed spacer induced membrane deformation on the performance of pressure retarded osmosis (PRO): implications for PRO process operation. Journal of Membrane Science 445, 170-182.

Smith, A.L., Skerlos, S.J. and Raskin, L. (2013) Psychrophilic anaerobic membrane bioreactor treatment of domestic wastewater. Water Research 47(4), 1655-1665.

Smith, A.L., Stadler, L.B., Love, N.G., Skerlos, S.J. and Raskin, L. (2012) Perspectives on anaerobic membrane bioreactor treatment of domestic wastewater: A critical review. Bioresource Technology 122, 149-159.

Tian, Y., Ji, C., Wang, K. and Le-Clech, P. (2014) Assessment of an anaerobic membrane bio-electrochemical reactor (AnMBER) for wastewater treatment and energy recovery. Journal of Membrane Science 450, 242-248.

Wang, H.M., Davidson, M., Zuo, Y. and Ren, Z.Y. (2011) Recycled tire crumb rubber anodes for sustainable power production in microbial fuel cells. Journal of Power Sources 196(14), 5863-5866.

Xiao, D., Tang, C.Y., Zhang, J., Lay, W.C.L., Wang, R. and Fane, A.G. (2011) Modeling salt accumulation in osmotic membrane bioreactors: implications for FO membrane selection and system operation. Journal of Membrane Science 366(1-2), 314-324.

Xie, M., Nghiem, L.D., Price, W.E. and Elimelech, M. (2014) Toward resource recovery from wastewater: Extraction of phosphorus from digested sludge using a hybrid 
574 forward osmosis-membrane distillation process. Environmental Science \& 575 Technology Letters 1(2), 191-195.

576

577

578

579

580

581

582

583

584

Xie, M., Shon, H.K., Gray, S.R. and Elimelech, M. (2016) Membrane-based processes for wastewater nutrient recovery: technology, challenges, and future direction. Water Research 89, 210-221.

Xue, W.C., Tobino, T., Nakajima, F. and Yamamoto, K. (2015) Seawater-driven forward osmosis for enriching nitrogen and phosphorous in treated municipal wastewater: effect of membrane properties and feed solution chemistry. Water Research 69, 120-130.

Zhang, M.M., Hou, D.X., She, Q.H. and Tang, C.Y.Y. (2014) Gypsum scaling in pressure retarded osmosis: experiments, mechanisms and implications. Water Research 48, 387-395.

Zhang, X.Y., He, W.H., Ren, L.J., Stager, J., Evans, P.J. and Logan, B.E. (2015) COD removal characteristics in air-cathode microbial fuel cells. Bioresource Technology 176, 23-31. 


\section{List of Figures}

593 Figure 1. Schematic diagram of the MEC/MRC-OMBR system. The microbial 594 electrochemical module was firstly operated in MEC mode followed by MRC mode with 595 the addition of nutrient recovery chambers. Detailed schematics of MEC and MRC

Figure 2. Time-course changes of membrane water flux (top) and solution conductivity (bottom) of the bulk or nutrient recovery solution during two-stage operation (MEC/MRC-OMBR).

Figure 3. Time-course changes of COD concentration in the OMBR bulk solution and draw solution, as well as COD removal during two stage operation (MEC/MRC-OMBR).

Figure 4. (A) Time-course changes of $\mathrm{NH}_{3}-\mathrm{N}$ (top) and $\mathrm{PO}_{4}-\mathrm{P}$ (bottom) concentrations in the OMBR bulk, draw solution and nutrient recovery solution, respectively. (B) $\mathrm{NH}_{3}-\mathrm{N}$ (top) and $\mathrm{PO}_{4}-\mathrm{P}$ (bottom) removal from the bulk solution and recovery in the nutrient recovery solution.

Figure 5. (A) Time-course changes of current and Columbic efficiency in the MEC/MRCOMBR system; (B) Interactive effects of COD and solution conductivity on current production.

Figure 6. Time-course changes of dissolved $\mathrm{CH}_{4}$ in the OMBR bulk and draw solution and $\mathrm{CH}_{4}$ yield during two-stage operation (MEC/MRC-OMBR). 


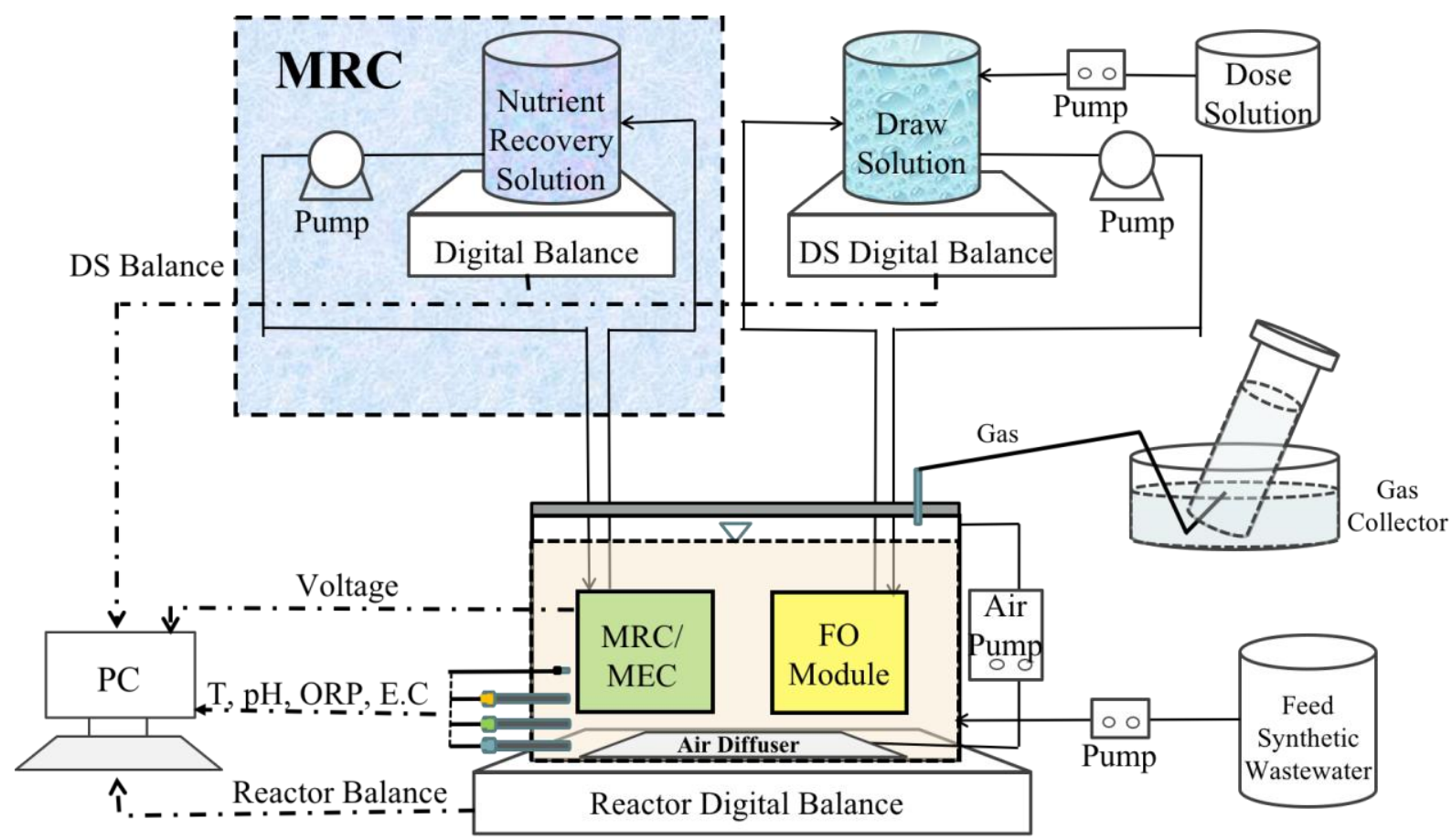

619 


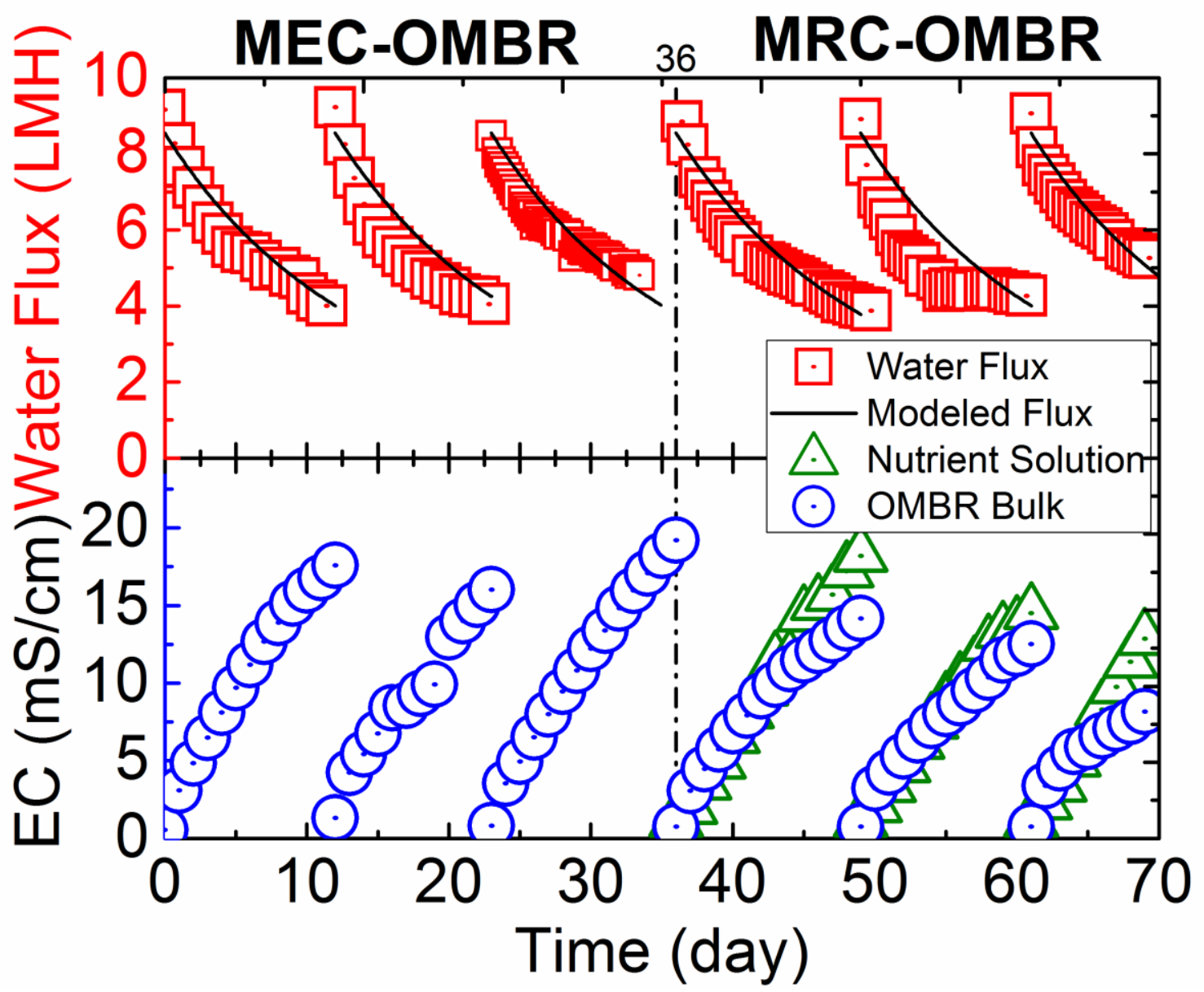

621 


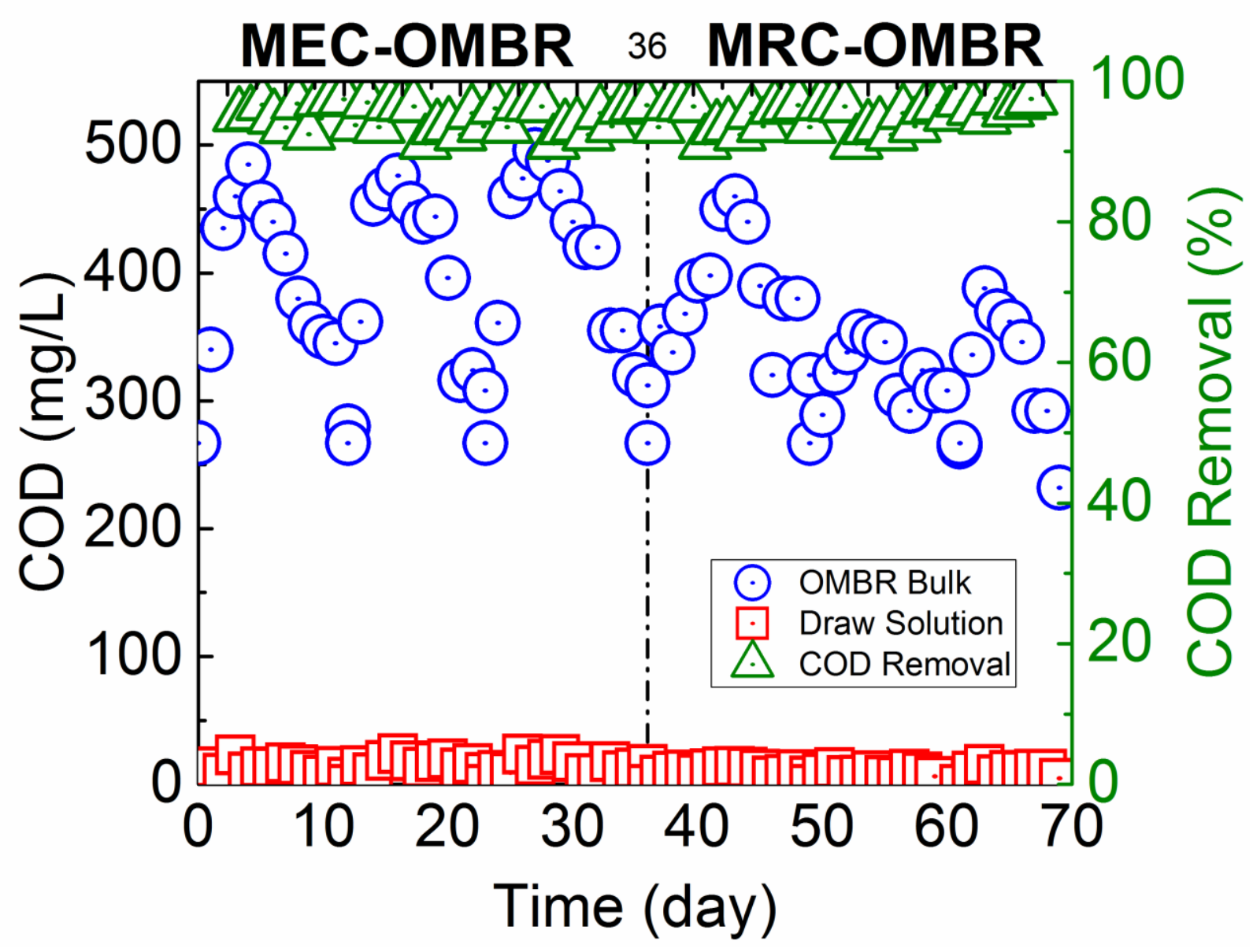

623 


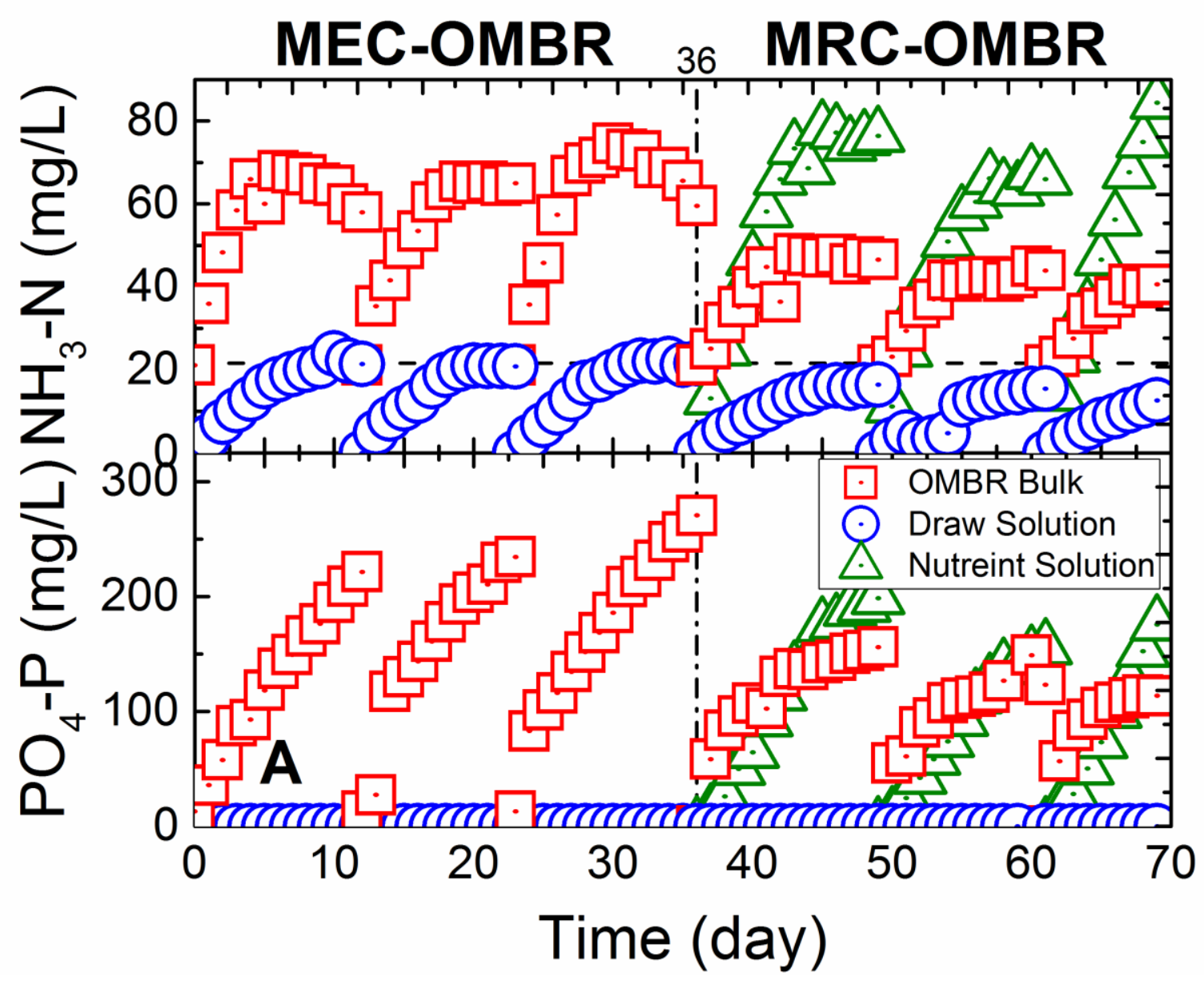

625 


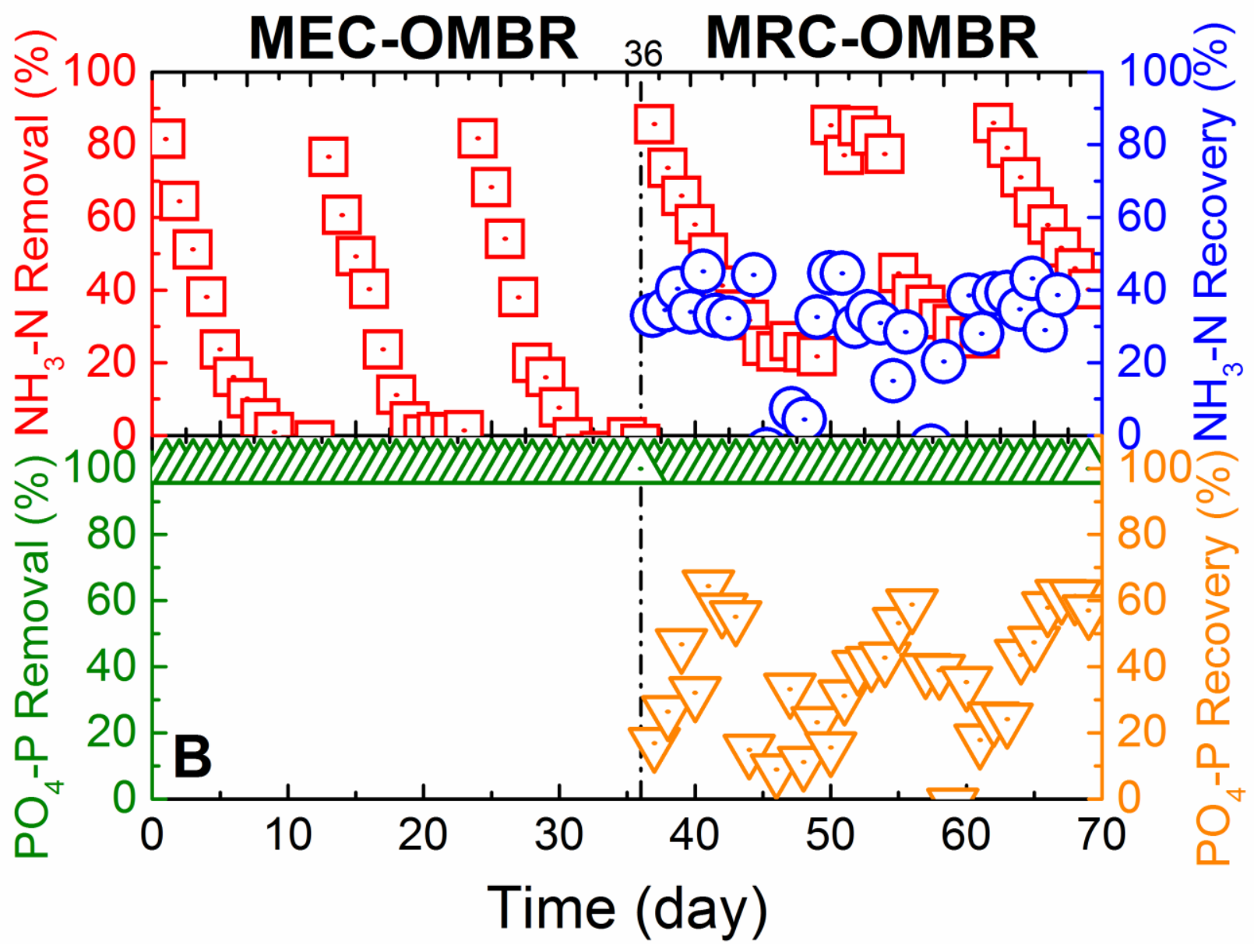

627 


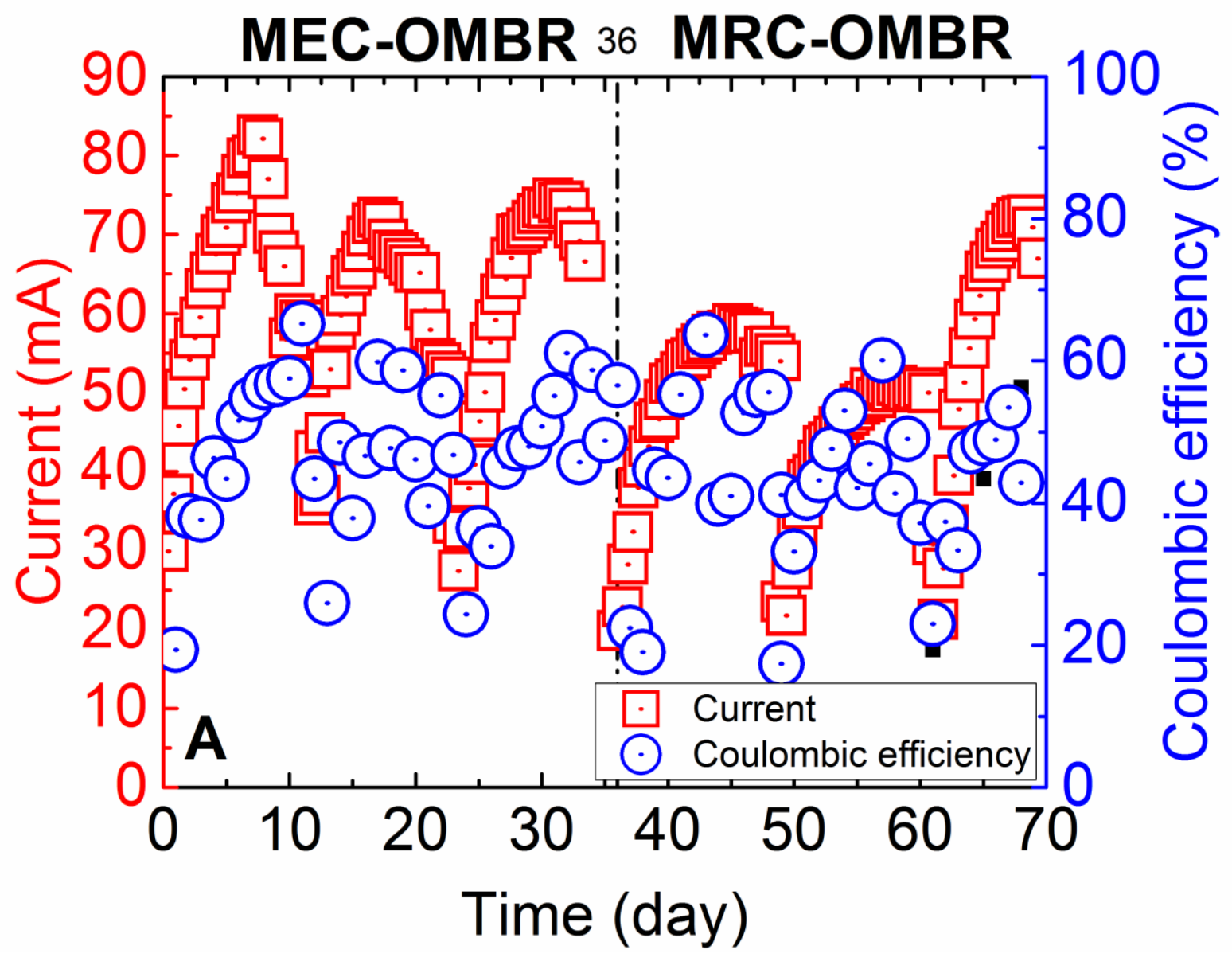

629 


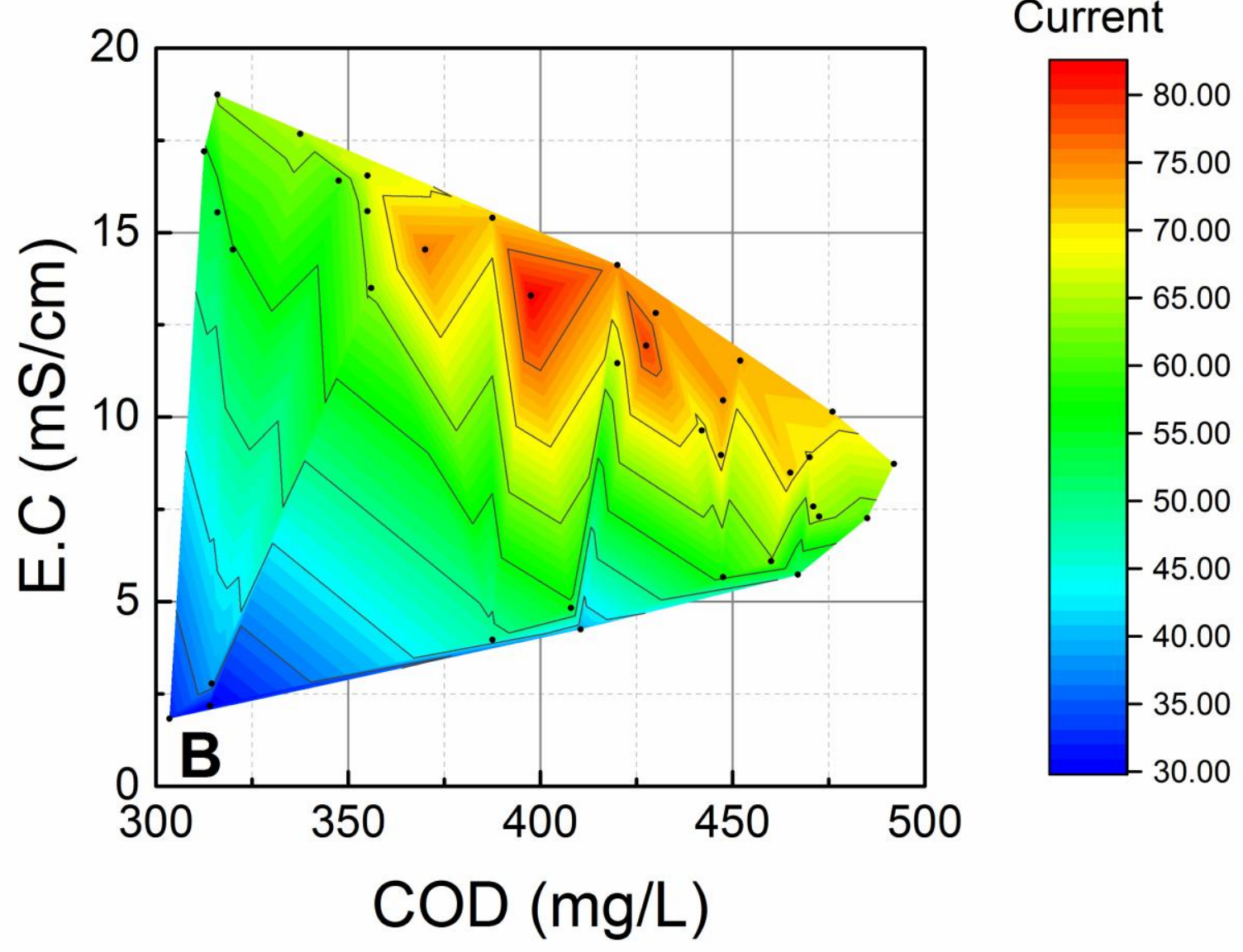

630

631 


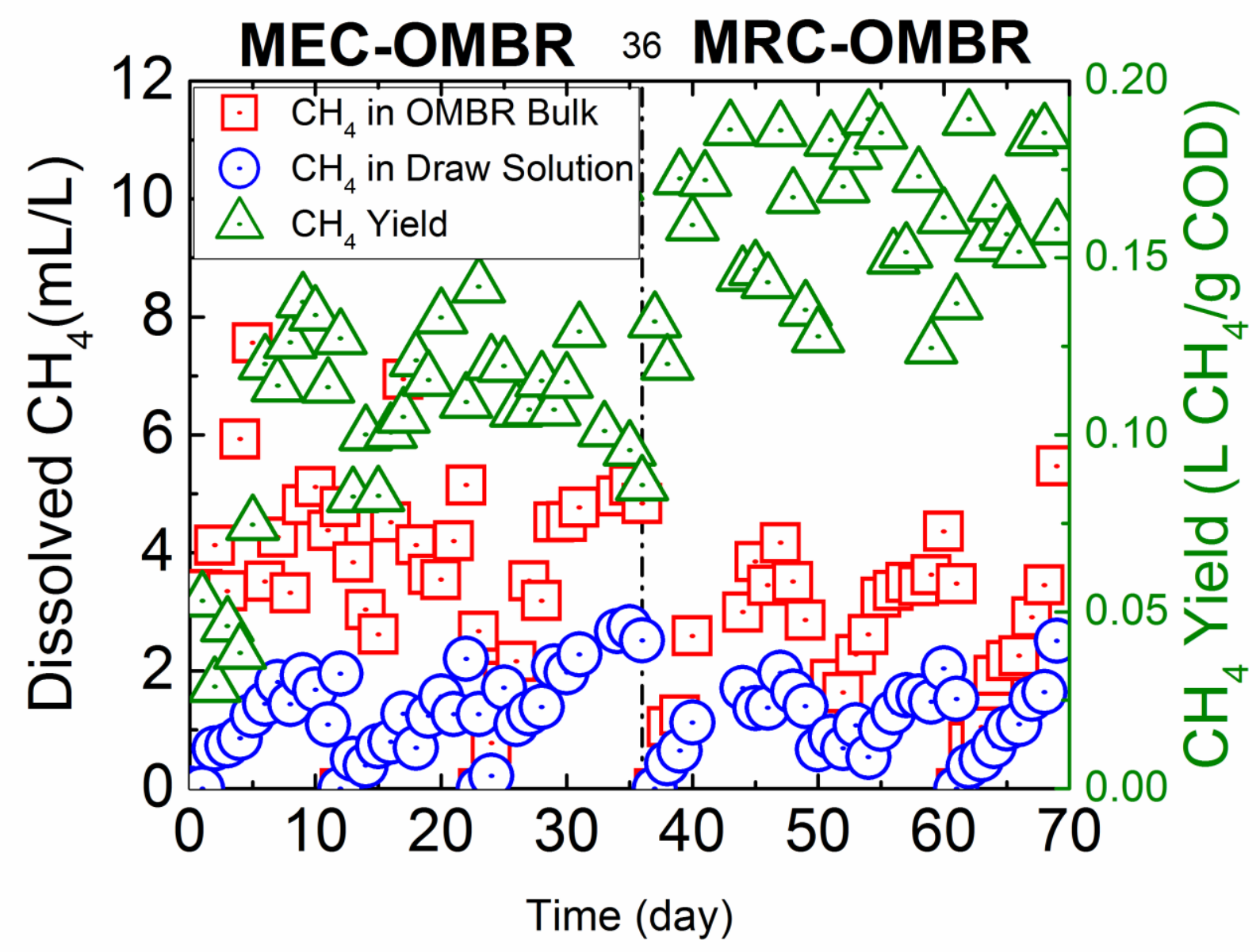

633 


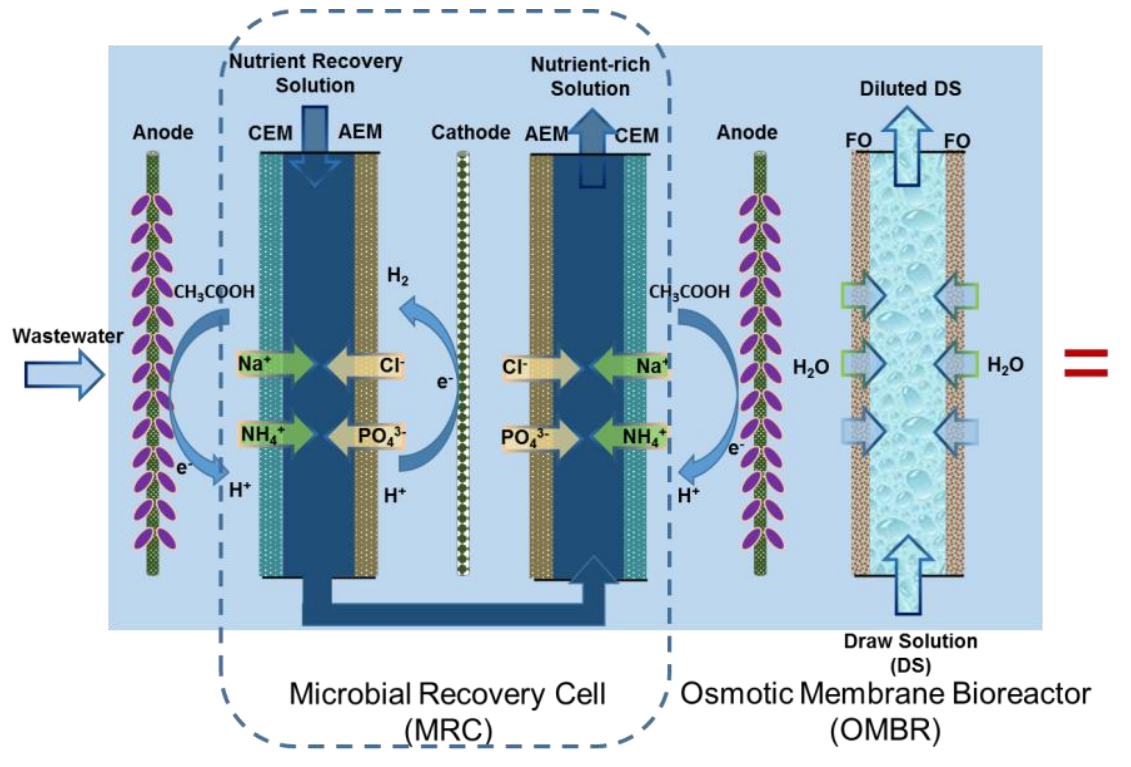

1) Boosted Current Density

2) Lower Fouling

3) Biogas Production

4) Nutrients Recovery

5) Improved Effluent Quality

6) Enhanced Methane Yield

MRC-OMBR

Mutual Benefits 